\title{
$58 \%$ of people recovering from a major depressive episode are unlikely to relapse after 5 years
}

Kanai T, Takeuchi H, Furukawa TA, et al. Time to recurrence after recovery from major depressive episodes and its predictors. Psychol Med 2003;33:839-45.

What is the time to recurrence after recovery from an initial episode of major depressive disorder?

METHODS

1

Design: Prospective multicentre cohort study.

Setting: 23 centres across Japan; enrolment December 1992 to December 1995.

Patients: 95 people with a single or recurrent episode of a major depressive disorder (DSM-IV criteria). People were included if they were in a depressive or manic state at the time of enrolment; $>18$ years of age. Exclusions: received antidepressant or antipsychotic medication in the preceding 3 months, and any condition making detailed psychopathological assessment difficult. Mean age of inception cohort was 44.3 years with $59 \%$ women.

Prognostic factors: After recovery from the initial episode, people were considered to have relapsed if they met DSM-IV criteria for major depressive episode, manic episode, or hypomanic episode. In addition, people were considered to have relapsed into a "subthreshold" depressive episode if they did not yet meet the criteria for a major depressive episode, yet had $>2$ symptoms or had 1-2 symptoms that were graver than mild degree, for one month.

Outcomes: Time to recurrence after recovery (defined as 2 consecutive months with no more than one or two mild depressive symptoms) from the initial depressive episode.

$\longrightarrow$ Follow up period: Six years.

\section{MAIN RESULTS}

Of the 82 people $(86.3 \%)$ who had recovered from the initial major depressive episode by 72 months of follow up, 50 (61.0\%) experienced a subthreshold relapse and 31 (37.8\%) experienced a full relapse (see table). The median time (at 72 months) between end of index episode and the beginning of the subthreshold depressive episode was 34.3

Table Subsequent outcomes in 82 people who recovered from a major depressive episode during 72 months follow up.

\begin{tabular}{|c|c|c|c|c|}
\hline & $\begin{array}{l}\text { Relapse } \\
\text { n (\%) }\end{array}$ & $\begin{array}{l}\text { No } \\
\text { Relapse } \\
\text { n (\%) }\end{array}$ & $\begin{array}{l}\text { Lost to follow up } \\
\text { without ever } \\
\text { reporting a } \\
\text { relapse, } \mathrm{n}(\%)\end{array}$ & $\begin{array}{l}\text { Cumulative } \\
\text { probability of } \\
\text { remaining well at } \\
60 \text { months }(95 \% \mathrm{Cl})\end{array}$ \\
\hline $\begin{array}{l}\text { Full relapse } \\
\text { Sub- } \\
\text { threshold } \\
\text { relapse }\end{array}$ & $\begin{array}{l}31(38 \%) \\
50(61 \%)\end{array}$ & $\begin{array}{l}19(23 \%) \\
12(15 \%)\end{array}$ & $\begin{array}{l}32(39 \%) \\
20(24 \%)\end{array}$ & $\begin{array}{l}58 \% \text { (46 to } 70 \%) \\
35 \% \text { (23 to } 47 \%)\end{array}$ \\
\hline
\end{tabular}

For correspondence: Professor Toshi A Furukawa, Department of Psychiatry, Nagoya City University Medical School, Mizuho-cho, Mizuho-ku, Nagoya, Japan

Sources of funding: this study was supported by research grants for Nervous and Mental Disorders from the Ministry of Health, Labour and Welfare, Japan. months ( $95 \%$ CI 27.6 to 41.0 months) and to the beginning of the depressive episode was 49.7 months (95\% CI 43.4 to 55.9 months).

\section{CONCLUSIONS}

Although the majority of people recovering from a major depressive episode are unlikely to suffer a full relapse within 60 months, most will not remain symptom free over the same time period.

Commentary

$\square$ igh rates of relapse/recurrence have been well documented in US and European samples of patients who recover from an index episode of major depressive disorder (MDD). ${ }^{1-4}$ These data, coupled with the detrimental effects and high costs of MDD (to both individuals and society), underscore the importance of predicting and preventing depression recurrence. This report of the naturalistic course of MDD in a prospectively followed Japanese sample is an important addition to the extant literature.

Several key findings deserve mention. First, the rate of full relapse after recovery was lower than that reported in other 5 year follow up trials. Kanai et al hypothesised that their sample was less chronic/recurrent at study entry compared with earlier studies. Unfortunately, they failed to present relevant data (eg, number of previous episodes) to help the reader assess this claim. Second, a majority (68\%) of participants reported elevated symptomatology (even if not a full relapse) over the follow up period. It is important to note that subthreshold depressive symptoms have been associated with significant functional impairment. ${ }^{5}$ Finally, only a clinical rating of depression severity at recovery predicted "subthreshold relapse" and no investigated variables predicted full relapse. Previous research suggests that personality disorder pathology reliably predicts MDD recurrence such that people with elevated levels of Axis II pathology experience a shortened time to recurrence. ${ }^{67}$ Examining this potential predictor would enhance the clinical significance of the study.

Advantages of the study design include a multicentre recruitment strategy that provides a sample likely to be a heterogeneous representation of the disorder. Additionally, the analysis of both time to "subthreshold" relapse and full relapse offers unique data on the reemergence of symptoms (and presumed decline in functioning) prior to the experience of a new depressive episode. Although lower than previous findings, the significant rate of both full and subthreshold relapse emphasises the importance of programmes focused on the prevention of MDD relapse/recurrence. Additional research is essential for determining how to predict who is at highest risk, and how best to prevent relapse in these individuals.

WE Craighead, AL Brosse, ES Sheets University of Colorado, Boulder, CO, USA

1 Klerman GL. The current age of youthful melancholia: evidence for increase in depression among adolescents and young adults in the national comorbidity survey. Depress Anxiety 1988;7:3-14.

2 Wickramaratne $\mathrm{P}$, Weissman $\mathrm{M}$, Leaf $\mathrm{PJ}$, et al. Age, period and cohort effects on the risk of major depression: results from five United States communities. J Clin Epidemiol 1989:42:333-43.

3 Weissman MM, Bland RC, Canino GJ, et al. Cross-national epidemiology of major depression and bipolar disorder. JAMA 1996;276:293-9.

4 Lewinsohn PM, Rohde P, Seeley JR, et al. Age-cohort changes in the lifetime occurrence of depression and other mental disorders. J Abnorm Psychol 1993:102:110-20.

5 Judd LL, Akiskal HS, Paulus MP. The role and clinical significance of subsyndromal depressive symptoms (SSD) in unipolar major depressive disorder. J Affect Dis 1997:45:5-18.

6 Ilardi SS, Craighead WE, Evans DD. Modeling relapse in unipolar depression: the effects of dysfunctional cognitions and personality disorders. $J$ Consult Clin Psychol 1997;65:381-91.

7 Hart AB, Craighead WE, Craighead LW. Predicting recurrence of major depressive disorder in young adults: a prospective study. J Abnorm Psychol 2001;110:633-43. 